\title{
Mimotope mapping as a complementary strategy to define allergen IgE-epitopes: Peach Pru p 3 allergen as a model
}

\author{
Luis F. Pacios , Leticia Tordesillas , Javier Cuesta-Herranz , \\ Esther Compes , Rosa Sánchez-Monge , Arantxa Palacín , \\ Gabriel Salcedo , Araceli Díaz-Perales \\ Unidad de Química y Bioquímica, Departamento de Biotecnología, E.T.S. Ingenieros de Montes, Madrid, Spain \\ Unidad de Bioquímica, Departamento de Biotecnología, E.T.S. Ingenieros Agrónomos, Madrid, Spain \\ Servicio de Alergia, Fundación Jiménez Día, Madrid, Spain
}

\begin{abstract}
Lipid transfer proteins (LTPs) are the major allergens of Rosaceae fruits in the Mediterranean area. Pru p 3, the LTP and major allergen of peach, is a suitable model for studying food allergy and amino acid sequences related with its IgE-binding capacity. In this work, we sought to map IgE mimotopes on the structure of Pru p 3, using the combination of a random peptide phage display library and a three-dimensional modelling approach. Pru p 3-specific IgE was purified from 2 different pools of sera from peach allergic patients grouped by symptoms (OAS-pool or SYS-pool), and used for screening of a random dodecapeptide phage display library. Positive clones were further confirmed by ELISA assays testing individual sera from each pool. Three-dimensional modelling allowed location of mimotopes based on analysis of electrostatic properties and solvent exposure of the Pru p 3 surface. Twenty-one phage clones were selected using Pru p 3-specific IgE, 9 of which were chosen using OAS-specific IgE while the other 12 were selected with systemic-specific IgE. Peptide alignments revealed consensus sequences for each pool: $\mathrm{L} 37$ R39 T40 P42 D43 R44 A46 P70 S76 P78 Y79 for OAS-IgE, and N35 N36 L37 R39 T40 D43 A46 S76 I77 P78 for systemic-IgE. These 2 consensus sequences were mapped on the same surface of Pru p 3, corresponding to the helix 2-loop-helix 3 region and part of the non-structured C-terminal coil. Thus, 2 relevant conformational IgE-binding regions of Pru $\mathrm{p} 3$ were identified using a random peptide phage display library. Mimotopes can be used to study the interaction between allergens and IgE, and to accelerate the process to design new vaccines and new immunotherapy strategies.
\end{abstract}

Keywords: Lipid transfer protein; Pru p 3; Mimotopes; IgE-epitope; 3D modelling; Solvent exposure; Electrostatic potential; Allergen surface

\section{Introduction}

Fruits, particularly peach, are the foods most frequently involved in allergic reactions in the adult population from the Mediterranean area (Ortolani et al., 1988; Kanny et al., 2001; Cuesta-Herranz et al., 1998; Cuesta-Herranz et al., 2000). The major peach allergen, named Pru p 3, belongs to the lipid transfer protein (LTP) panallergen family (Sanchez-Monge et al., 1999; Pastorello et al., 1999). This protein family is widely distributed throughout the plant kingdom and includes small basic polypeptides $(9 \mathrm{kDa} ; \mathrm{p} I \sim 9)$ with 8 conserved cysteine residues forming 4 disulphide bridges (Salcedo et al., 2004; Salcedo et al., 2007). LTPs are important allergens not only in Rosaceae fruits, but also in other plant foods, such as vegetables, cereals and nuts (Salcedo et al., 2004; Salcedo et al., 2007). Furthermore, LTPs have also been involved in some pollinosis and in cross-reactivity between plant foods and pollens (Salcedo et al., 2007; Zuidmeer and van Ree, 2007), as well as in occupational asthma (baker's asthma) (Palacin et al., 2007).

The standard folding of plant LTP allergens is an all- $\alpha$ type compact structure comprising $4 \alpha$-helices, firmly held by a network of the 4 conserved disulphide bridges, and a non- 
structured C-terminal coil (Salcedo et al., 2007; Pasquato et al., 2006). This compact structure is consistent with their uncommon resistance to heat treatment and digestive proteolytic attack, thus suggesting that LTP allergens retain most of their immunogenic and allergenic capacity after passing through the gastrointestinal tract (Salcedo et al., 2007; van Ree, 2002). These characteristics could explain the severe systemic clinical symptoms usually associated with LTP-mediated allergies (Fernandez-Rivas et al., 2003; Pastorello and Robino, 2005), and have led to the proposition of LTPs as a model family of true food allergens, being peach Pru p 3 the prototypic member (Salcedo et al., 2007; van Ree, 2002).

The compact folding and high stability of LTP allergens suggest that conformational IgE-epitopes represent their main IgE-binding structural motifs. Very limited information on IgEepitopes of plant food allergens belonging to the LTP family is available at present. Only 3 sequential epitopes of Pru p 3 have been located analyzing synthetic decapeptides deduced from its amino acid sequence (Garcia-Casado et al., 2003). The restrictions inherent to this approach indicate that potentially relevant IgE-binding regions of this allergen, particularly conformational epitopes formed by sequentially discontinuous amino acid residues, have not been described yet. Most of antibody epitopes are described to be conformational and hence, sequential approaches may render limited information, besides might exhibit reduced antibody-affinity (Aalberse, 2000).

New strategies have been tested in the last years to study and characterize regions with IgE-binding capacity. Phage display has shown to be a powerful tool to uncover conformational mimic epitopes or mimotopes from random peptide phage libraries (Luzzago et al., 1993; Folgori et al., 1994). Mimotope sequences would represent a region of the allergen that is recognized by IgE, thus representing a structural B-cell epitope (Ganglberger et al., 2000; Myers et al., 2000; Davies et al., 2000). Mimotopes could also be employed for the development of new immunotherapy strategies as design of peptide vaccines or specific treatments with hypoallergenic proteins (Jensen-Jarolim et al., 1998; Jensen-Jarolim et al., 1999).

The aim of the present work was to define ligands mimicking conformational epitopes on the Pru p 3 allergen and to analyze the location of such epitopes on its molecular surface by using phage-displayed peptide libraries.

\section{Methods}

\subsection{Patients and sera}

Sera from 23 peach allergic patients were tested in this study. Patients were selected at the Servicio de Alergia, Fundación Jiménez Díaz (Madrid) based on a convincing clinical history of allergic reactions after peach ingestion and a positive skin prick test (SPT) (Sub-Committee on Skin Tests of the European Academy of Allergology and Clinical Immunology, 1989) to response to peach (ALK-Abello, Madrid, Spain). On a second step, peach allergy was confirmed in all selected patients by an open oral challenge test to peach following the method previ- ously described (Cuesta-Herranz et al., 1998; Cuesta-Herranz et al., 2000). Finally, positive SPT response and specific IgE to Pru p 3 were also need to take part in the study. Demographic and clinical data of these patients are shown in Table 1. Sera were grouped in 2 pools according to peach allergic symptoms: OASpool (patients showing only oral allergy syndrome) and SYS (systemic)-pool (patients with, at least, one systemic reaction, with or without associated OAS). Systemic reactions included urticaria ( 8 patients), angioedema (4 patients) and asthma (2 patients). The study was approved by the Ethics Committee (Hospital Jimenez Diaz) and written informed consent was given by all the patients or their legal representatives.

\subsection{Purification of Pru p 3-specific IgE}

Expression of rPru p 3 in Pichia pastoris and isolation of the recombinant allergen was performed by methods previously described (Diaz-Perales et al., 2003). Purified rPru p 3 was quantified by means of the commercial bicinchoninic acid test (Pierce, Cheshire, UK) and used to isolate specific IgE from the OAS- and SYS-pool of sera. Briefly, $12 \mathrm{mg}$ of purified $\mathrm{rPru} p 3$ was dissolved in $0.1 \mathrm{~mol} / \mathrm{L} \mathrm{Na}_{2} \mathrm{CO}_{2}$ [pH 8.3] with $0.5 \mathrm{~mol} / \mathrm{L} \mathrm{NaCl}$. After washing with $1 \mathrm{mmol} / \mathrm{L} \mathrm{HCL}, \mathrm{BrCN}-$ activated Sepharose $4 \mathrm{~B}$ was incubated with the recombinant allergen at $4{ }^{\circ} \mathrm{C}$ overnight. Then, the matrix was packed and equilibrated with $50 \mathrm{mmol} / \mathrm{L}$ Tris- $\mathrm{HCl}[\mathrm{pH} 7.5]$. Ten millilitres of each serum pool (OAS or SYS) was applied to the rPru p 3affinity column. After washing with $50 \mathrm{mmol} / \mathrm{L}$ Tris- $\mathrm{HCl}[\mathrm{pH}$ 7.5], the binding-immunoglobulin was eluted with $0.1 \mathrm{~mol} / \mathrm{L}$ glycine [ $\mathrm{pH} 2.7]$ with $0.5 \mathrm{~mol} / \mathrm{L} \mathrm{NaCl}$. After elution, retained fraction was equilibrated with $1 \mathrm{~mol} / \mathrm{L}$ Tris-HCl [pH 8.5]. Pru p 3-specific $\operatorname{IgG}$ and $\operatorname{IgE}$ contained in the retained fraction were separated by affinity chromatography with a HiTrap Protein G HP (GE Healthcare). Purity of $\mathrm{IgE}$ and $\mathrm{IgG}$ fractions was checked by ELISA assays using each fraction as solid phase $(0.1 \mu \mathrm{g} / \mathrm{mL})$, and anti-human IgE-HRP polyclonal antibody (DAKO; $1 / 5000$ dilution). Values (OD units at $492 \mathrm{~nm}$ ) obtained in the OAS-pool were $1.24,2.07$ and 0.31 for the whole pool of sera, the specific $\operatorname{IgE}$ fraction and the specific $\operatorname{IgG}$ fraction, respectively, and $1.24,1.67$ and 0.22 for the whole pool of sera and the specific $\operatorname{IgE}$ and $\mathrm{IgG}$, respectively, in the case of the SYS-pool. A pool of sera from 5 atopic subjects with allergy to house dust mites but not to plant foods or pollens was used as negative control (OD units $=0.124$ ).

\subsection{Biopanning of phage display library and colony screening}

The Ph.D.-12 Phage Display Peptide Library $(2.7 \times$ $10^{9}$ clones; New England Biolabs) was used to select phage clones that bound Pru p 3-specific IgE. The M13-phage used contained a modified P8 coat protein, the most abundant in its surface, in which a random dodecapeptide had been inserted. Panning was performed following the manufacturer's instructions. Pru p 3-specific IgE coating plates were incubated with phages, and the bound clones were eluted with glycine buffer 
Table 1

Clinical data of the selected patients

\begin{tabular}{|c|c|c|c|c|c|c|c|}
\hline Patients & Age & Sex & OAS & SYS & Pollen allergy & Pru p 3 (SPT) & Specific-IgE to Pru p $3^{\mathrm{a}}$ (OD units) \\
\hline 1 & 23 & $\mathrm{~F}$ & + & - & - & + & 0.827 \\
\hline 2 & 20 & $\mathrm{~F}$ & + & - & + & + & 0.507 \\
\hline 3 & 21 & M & + & - & + & + & 0.640 \\
\hline 4 & 12 & $\mathrm{~F}$ & + & - & + & + & 0.634 \\
\hline 5 & 21 & $\mathrm{M}$ & + & - & + & + & 0.522 \\
\hline 6 & 34 & $\mathrm{~F}$ & + & - & + & + & 0.400 \\
\hline 7 & 37 & $\mathrm{~F}$ & + & - & + & + & 0.477 \\
\hline 8 & 32 & $\mathrm{M}$ & + & - & + & + & 0.927 \\
\hline 9 & 30 & $\mathrm{~F}$ & + & - & + & + & 0.647 \\
\hline 10 & 66 & $\mathrm{~F}$ & + & - & + & + & 1.204 \\
\hline 11 & 21 & $\mathrm{~F}$ & + & - & + & + & 0.367 \\
\hline 12 & 39 & $\mathrm{~F}$ & + & - & + & + & 0.420 \\
\hline 13 & 24 & $\mathrm{~F}$ & + & - & + & + & 1.317 \\
\hline 14 & 43 & $\mathrm{~F}$ & + & - & & + & 0.610 \\
\hline 15 & 33 & $\mathrm{~F}$ & + & $\mathrm{U}, \mathrm{AE}$ & - & + & 1.297 \\
\hline 16 & 4 & M & + & $\mathrm{U}$ & - & + & 0.767 \\
\hline 17 & 26 & M & + & $\mathrm{U}$ & + & + & 1.753 \\
\hline 18 & 45 & M & + & $\mathrm{U}, \mathrm{AE}$ & + & + & 0.840 \\
\hline 19 & 40 & $\mathrm{M}$ & - & $\mathrm{U}, \mathrm{AE}$ & + & + & 1.777 \\
\hline 20 & 13 & $\mathrm{~F}$ & + & U & + & + & 1.327 \\
\hline 21 & 11 & $\mathrm{M}$ & + & $\mathrm{U}$ & + & + & 1.023 \\
\hline 22 & 15 & $\mathrm{~F}$ & - & $\mathrm{U}, \mathrm{A}$ & + & + & 1.193 \\
\hline 23 & 26 & $\mathrm{~F}$ & - & $\mathrm{U}, \mathrm{AE}, \mathrm{A}$ & + & + & 0.437 \\
\hline
\end{tabular}

OAS: oral allergy syndrome, SYS: systemic symptoms, M: male, F: female, SPT: skin prick test, OD: optical density, U: urticaria, AE: angioedema, A: asthma.

a Values are means $(n=3$ ). OD higher than 0.189 units were considered positive (see Section 2 ).

(0.1 mol/L, pH 2.2). After 3 rounds of selection, 20 phage clones from each serum pool were isolated, amplified, and their reactivity tested with Pru p 3-specific IgE by means of capture ELISA, as described below. The amino acid sequences of inserted peptides were deduced by sequencing DNA of the selected clones with a specific $5^{\prime}$ primer: CGGGAGTATCAATCGCATTGC. The used method to DNA sequencing was the ABI PRISM Dye Terminator Kit and ABI 3100 sequencer (PerkinElmer Biosystem).

\subsection{ELISA assays}

Pru p 3-specific IgE was determined in each individual serum (1:3 dilution) from peach allergic patients by means of a previously described direct ELISA method (Diaz-Perales et al., 2003). rPru p $3(5 \mu \mathrm{g} / \mathrm{mL})$ was used as solid phase, and BSA (1\% in PBS buffer) as negative control. Specific IgE levels greater than 0.189 OD units (mean $[\mathrm{OD}]+3 \times$ S.D. to BSA) were considered positive. All tests were performed in triplicate.

The specificity of $\mathrm{IgE} / \mathrm{selected}$ phages recognition was confirmed by 2 different ELISA assays. First, plates were coated with the selected clones $\left(10^{8} \mathrm{PFU} /\right.$ well) and, after blocking, incubated with individual sera (1:3 dilution) from the selected patients, then with anti-human IgE-peroxidaseconjugated antibodies (DAKO; 1:5000 dilution), and finally revealed with peroxidase substrate buffer (DAKO). Second, Pru p 3-specific IgE $(10 \mu \mathrm{g} / \mathrm{mL})$-coated plates were treated with each selected clone $\left(10^{8} \mathrm{PFU} /\right.$ well), then with anti-M13-peroxidase- conjugated monoclonal antibody (GE Healthcare Bioscience; 1:1000 dilution), and finally revealed with peroxidase substrate buffer. The empty M13 phage clone was used as negative control, and OD values of greater than mean $[\mathrm{OD}]+3 \times$ S.D. to this negative control were considered positive. All tests were performed in triplicate.

\subsection{Location of mimotopes on the structure and surface of Prup 3}

Chain A of the X-ray structure of Pru p 3, PDB code 2B5S (Pasquato et al,, 2006), was used to compute the solvent-excluded surface (SES) with PyMOL 0.99 (pymol.sourceforge.net). SES areas and relative accessibility values of each residue with respect to reference data were calculated with Arvomol 4.0 (Pacios, 1994) as explained elsewhere (Pacios, 2001). The electrostatic Poisson-Boltzmann (PB) potential mapped onto the protein surface was obtained with APBS 0.4.0 (Baker et al., 2001) assigning AMBER99 (Wang et al., 2004) atomic charges and radii, including hydrogens that were added with PDB2PQR (Dolinsky et al., 2004). Fine (0.50 $\AA$ spacing) grids around the 1293 resulting atoms were used to solve the nonlinear PB equation in sequentialfocusing multigrid calculations in a mesh of 97 points per dimension at $298.15 \mathrm{~K}$ with dielectric constants 2 for the protein and 78.54 for water. Potential values are given in units of $k T$ per unit charge ( $k$, Boltzmann's constant; $T$, absolute temperature). Molecular graphics were rendered with PyMOL 0.99 . 


\section{Results}

\subsection{Selection of Pru p 3-specific IgE-binding phage clones}

Positive SPT response to Pru p 3 were observed in all 23 selected patients and significant specific $\operatorname{IgE}$ to this allergen found in all corresponding sera (Table 1). Two different serum pools were obtained according to the patients' symptoms: OASpool (sera 1-14) and SYS (systemic)-pool (sera 15-23). Pru p 3-specific $\operatorname{IgE}$ from each pool was purified by a two-step method of affinity chromatography, which included a Pru p 3-Sepharose column followed by a Hitrap Protein G HP Column to separate Pru p 3-specific IgE and IgG (see Section 2).

The purified Pru p 3-specific IgE fractions from both pools of sera were independently used to screen a random display peptide phage library to select IgE-binding phage clones. Twenty clones were chosen for each type of Pru p 3-specific IgE (OAS- or SYS-pool) after 3 rounds of selections. Sequencing of the DNA insertions of each selected clone rendered 9 different peptides for the purified specific IgE from the OAS-pool, and 12 distinct peptides for that from the SYS-pool. The amino acid sequences of all these peptides are shown in Table 2.

Several individual sera forming each pool recognized each selected phage clone (Table 2). Interestingly, 6 out of 9 clones selected with the OAS-pool-specific IgE, as well as 9 out of 12 clones with the SYS-pool-specific IgE, were recognized by more than $50 \%$ of the corresponding individual sera, thus supporting the selection procedure. None of the individual sera recognized the wild M13 phage (whose P8 coating protein was not modified by peptide insertion).

\subsection{Specificity of the binding between Prup 3-specific IgE and selected phage clones}

The specificity of the IgE/phage clone binding was further analyzed by means of ELISA assays using rPru p 3-specific IgEcoated plates incubated with each selected clone. The binding was detected with an anti-M13-peroxidase-conjugated monoclonal antibody. The results are summarized in Fig. 1. All the selected phage clones bound to the corresponding (OAS- or SYS-pool) rPru p 3-specific IgE. However, substantial differences in the absorbance among the selected clones were noticed, suggesting that some mimotopes showed more affinity to $\operatorname{IgE}$ than others.

\subsection{Identification of IgE-epitopes in the structure of Prup 3}

The amino acids of mimotope sequences were ordered according with the frequency of apparition. Thus, the most frequent amino acid (which appeared in the greater number

Table 2

Amino acid sequence of inserted peptides from the selected clones and their recognition by the individual sera forming each pool sera and alignment

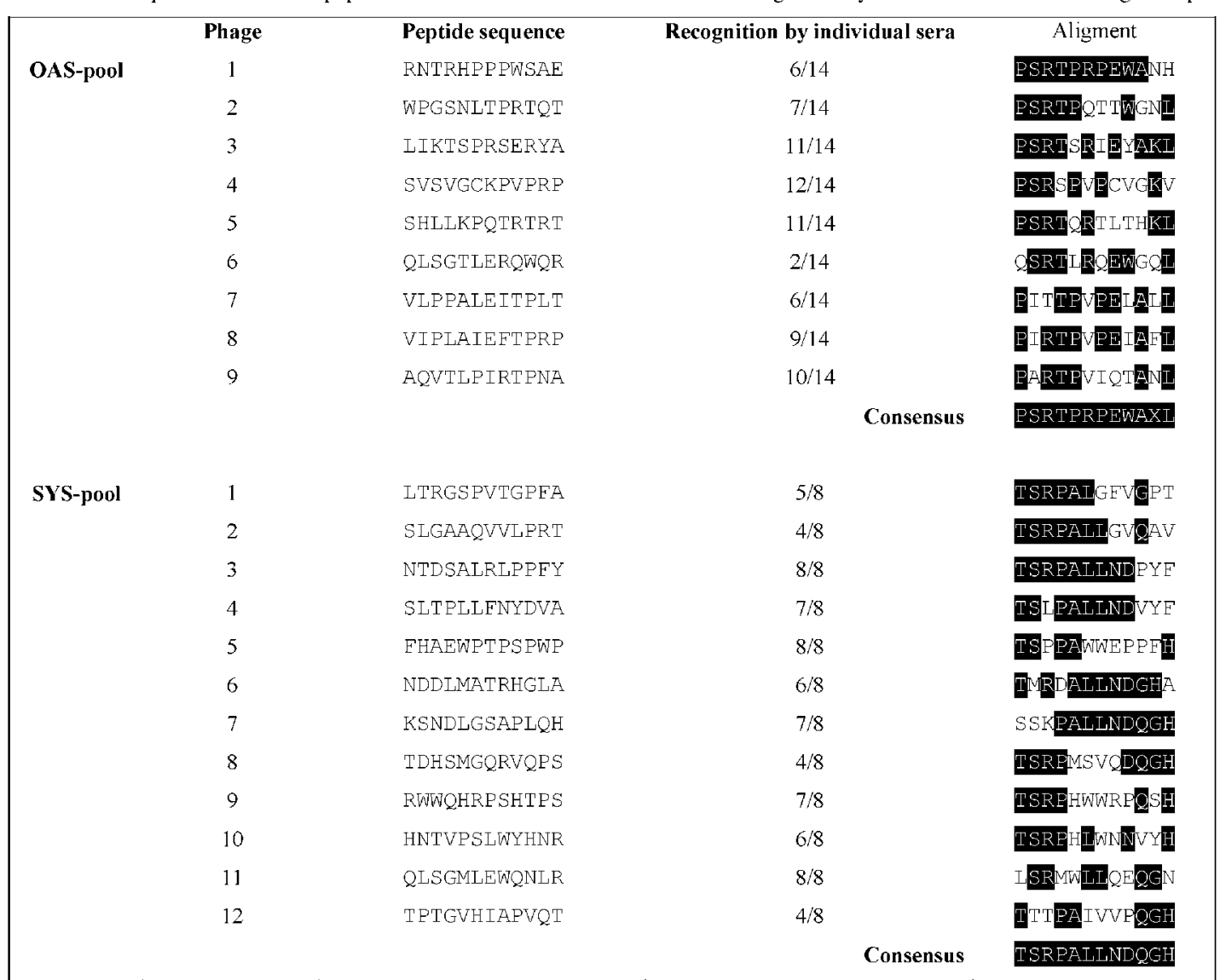

The peptide sequences are aligned in the right column and a consensus sequence for each group of peptides is remarked 


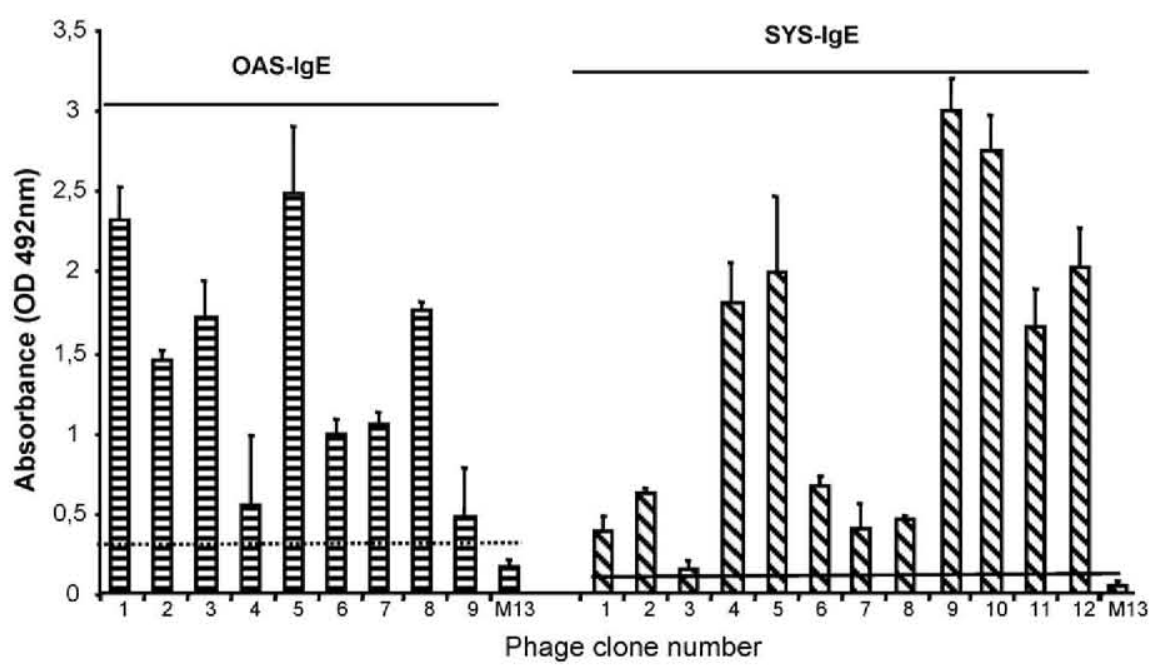

Fig. 1. Pru p 3-specific IgE/selected phage clone binding. ELISA assays were performed using the corresponding specific IgE (OAS or SYS) as solid phase and each selected phage clones. Empty (non-modified) M13 clone was tested as negative control. Means $(n=3)$ and S.D. (bars) are represented. Horizontal lines indicate cut-off values (see Section 2).

of clones) was ordered in the first position. The alignment of this sequences (Table 2) revealed a remarkable similarity that leads to the consensus sequences PSRTPRPEWAXL for OAS-IgE selected clones and TSRPALLNDQGH for SYS-IgE clones. Amino acids in these 2 sequences were mapped onto the structure of Pru p 3 (Pasquato et al., 2006) by selecting residues located at the protein surface that exhibit proper electrostatic and solvent exposure features (Garcia-Casado et al., 2003; Dolinsky et al., 2004) and choosing analogous amino acids to replace those absent in Pru p 3 (D for E or $\mathrm{Y}$ for $\mathrm{W}$, for instance). The resulting mimotope for OAS$\mathrm{IgE}$ clones was composed of the residues (arranged in Pru p 3 sequence ordering) $\mathrm{L}_{37} \mathrm{R}_{39} \mathrm{~T}_{40} \mathrm{P}_{42} \mathrm{D}_{43} \mathrm{R}_{44} \mathrm{~A}_{46} \mathrm{P}_{70} \mathrm{~S}_{76} \mathrm{P}_{78} \mathrm{Y}_{79}$ whereas for SYS-IgE clones the mimotope lacks the last $\mathrm{H}$ (Pru p 3 has no histidines) and was composed of the residues $\mathrm{N}_{35} \mathrm{~N}_{36} \mathrm{~L}_{37} \mathrm{R}_{39} \mathrm{~T}_{40} \mathrm{D}_{43} \mathrm{~A}_{46} \mathrm{~S}_{76} \mathrm{I}_{77} \mathrm{P}_{78}$. These amino acids are
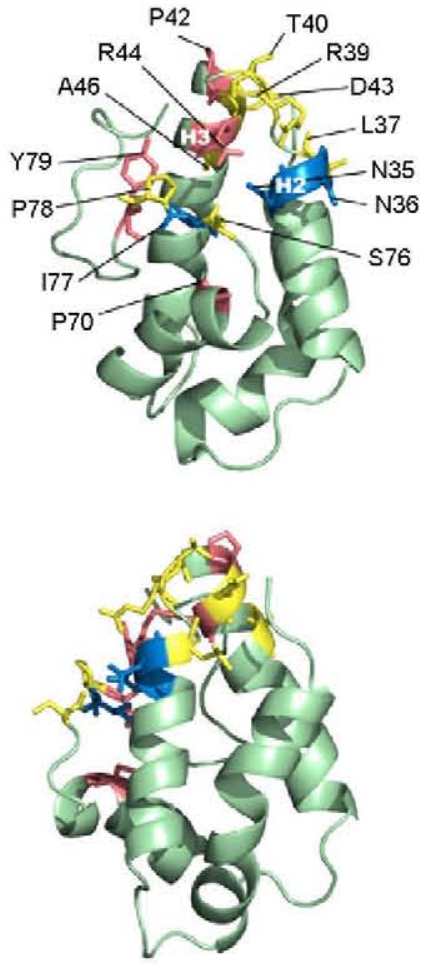

(A)
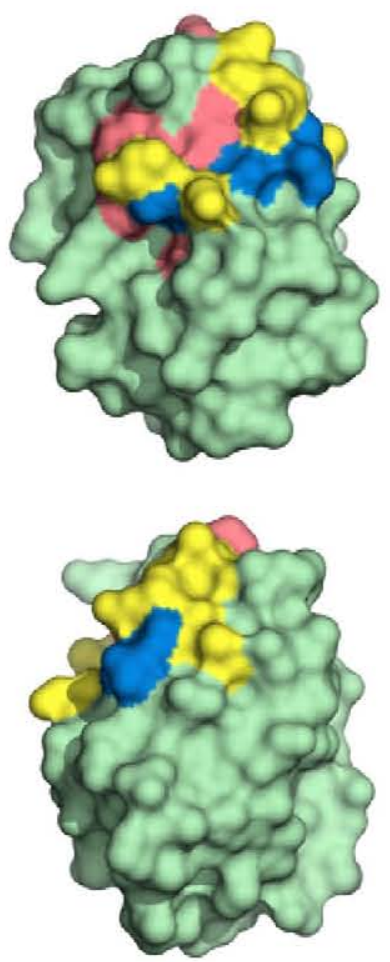

(B)

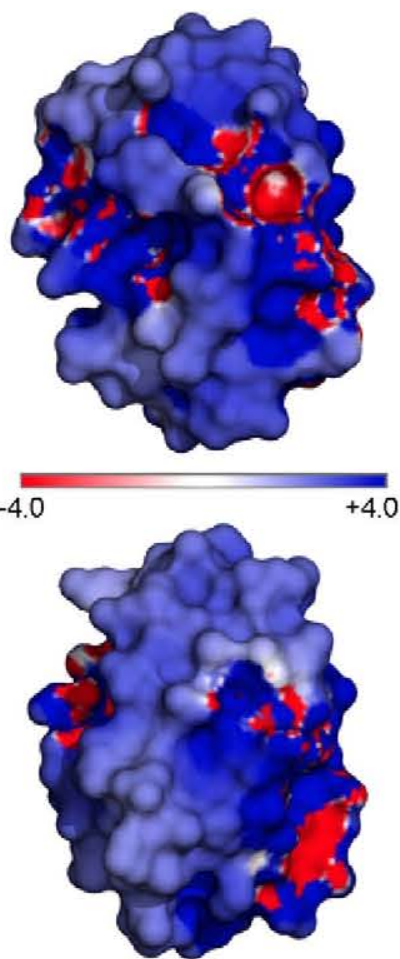

(C)

Fig. 2. Amino acids in OAS and SYS mimotopes on Pru p 3. (A) Ribbon diagrams, (B) Surfaces. Residues shared by both mimotopes are coloured yellow, those present only in the OAS mimotope are coloured salmon and those present only in the SYS mimotope are coloured blue. (C) Electrostatic PB potential mapped onto the surface. Bottom views of Fig. $2 \mathrm{~A}$ through $\mathrm{C}$ are derived from upper views by means of a clockwise $90^{\circ}$ rotation about a vertical axis. 
located in 2 separate parts of the structure of Pru p 3 (Fig. 2A): the close ends of helices 2 and 3 together with their connecting loop (residues 35-46) and a short segment in the non-structured coil at the C-terminus (residues 76-79).

Despite being structurally far apart, the mimotopes happen to be located at the same surface region spanning a contiguous area of $910 \AA^{2}$ (the total protein area is $4850 \AA^{2}$ ) in which 9 out of the 14 residues have percentages of exposure to solvent greater than $60 \%$. The mimotopes share 7 residues, $\mathrm{L}_{37}, \mathrm{R}_{39}, \mathrm{~T}_{40}, \mathrm{D}_{43}$, $\mathrm{A}_{46}, \mathrm{~S}_{76}$ and $\mathrm{P}_{78}$, that form a connected surface with an exposure to the solvent noticeably greater than the non-overlapping residues $\mathrm{R}_{44}, \mathrm{P}_{70}$ and $\mathrm{Y}_{79}$ in the OAS-IgE mimotope, and $\mathrm{N}_{35}$ and $\mathrm{I}_{77}$ in the SYS-IgE mimotope (Fig. 2B). These results agree with the known fact that B-cell epitopes are usually associated with turns or loops and exposed regions protruding from protein surfaces and strongly suggest that OAS and SYS mimotopes are involved in the same IgE-binding region of Pru p 3. The surface covered by the mimotopes exhibits an electrostatic potential in which intermediate positive values dominate (Fig. 2C) although $\mathrm{N}_{35}$ and $\mathrm{R}_{44}$ show greater electropositive values (Fig. 2C, top). Small electronegative areas are noticed around $\mathrm{N}_{36}$ and the unique acidic residue in Pru p 3, D 43 (Fig. 2C, top), as well as in a large part of the $\mathrm{S}_{76}$ area (Fig. 2C, bottom) which is by far the most protruding residue (94\% exposure to the solvent). This way, the area spanned by these 5 residues forms a patch with alternating electrostatic potential in the vicinity of the H2H3 loop.

\section{Discussion}

Results of this manuscript showed at the first time identification of 2 relevant conformational epitopes of Pru $\mathrm{p} 3$ by using a random peptide phage display library. The importance of these findings is based on this information will help to generate hypoallergenic variants of major allergens which might be potentially used in specific immunotherapy (Ferreira et al., 2002; Larche et al., 2006). A previous knowledge of the B ( $\operatorname{IgE})$ epitopes, both sequential and conformational, as well as of T-cell epitopes, is required to design these engineered variants. This information is very scarce for IgE-epitopes (Garcia-Casado et al., 2003) and non-existing for the T-cell epitopes in the case of plant food LTP allergens. Novel data on conformational epitopes of peach Pru p 3, the allergen model of the plant food LTP family, have been obtained here by means of mimotope identification. Analysis of phage display random peptide libraries using specific IgE to an allergen allows uncover peptides that mimic the binding site for $\mathrm{IgE}$ but do not correspond to the linear sequence of the cognate allergen. These peptides are known as mimotopes and usually represent conformational epitopes (Riemer et al., 2004).

Peach allergy mediated by Pru p 3 can be related with mild reactions restricted to the orapharyngeal cavity (oral allergy syndrome, OAS), frequently associated with pollinosis (Ortolani et al., 1988; Cuesta-Herranz et al., 2000; Zuidmeer and van Ree, 2007; Fernandez-Rivas et al., 2003). Besides, severe systemic symptoms are developed by many patients (around 30\%) suffering this allergy, with or without associated pollinosis (Zuidmeer and van Ree, 2007; Fernandez-Rivas et al., 2003; FernandezRivas et al., 1997). Therefore, Pru p 3-specific IgE was isolated from 2 different serum pools: OAS-pool (including sera from patients who showed exclusively OAS), and SYS-pool (formed by sera from patients who had suffered at least a systemic reaction, with or without linked OAS). Specific IgE from both pools was independently used to perform 3 sequential rounds of parallel screenings of a phage-displayed random peptide library. Nine and 12 different clones were finally selected for OASand SYS-IgE, respectively, after DNA sequencing of $20 \mathrm{IgE}-$ binding clones detected with each pool. Most of the selected clones were recognized by more than $50 \%$ of the individual sera that comprise the corresponding pool, thus highlighting the specificity of the selection method and the relevance of the detected mimotopes. Furthermore, all selected phage clones bound the isolated Pru p 3-specific IgE (from the OAS- or SYSpool), although different relative responses (OD units) were observed, probably reflecting differences in the mimotope affinity to $\operatorname{IgE}$.

The alignment of amino acid of the selected peptides generated 2 consensus mimotopes (Table 2) which were mapped onto the structure of Pru p 3 to the fragments $\mathrm{L}_{37} \mathrm{R}_{39} \mathrm{~T}_{40} \mathrm{P}_{42} \mathrm{D}_{43} \mathrm{R}_{44} \mathrm{~A}_{46} \mathrm{P}_{70} \mathrm{~S}_{76} \mathrm{P}_{78} \mathrm{Y}_{79}$ for OAS-IgE and $\mathrm{N}_{35} \mathrm{~N}_{36} \mathrm{~L}_{37} \mathrm{R}_{39} \mathrm{~T}_{40} \mathrm{D}_{43} \mathrm{~A}_{46} \mathrm{~S}_{76} \mathrm{I}_{77} \mathrm{P}_{78}$ for SYS-IgE clones (Fig. 2A). These 2 sequences share 7 residues and correspond to amino acids located at the loop $\mathrm{H} 2 \mathrm{H} 3$ and at a short segment in the C-terminal coil. In spite of their separation in the 3D allergen structure, both mimotopes span contiguous areas at the same region of the protein (Fig. 2B), a result which points to their common involvement in the interaction with IgE. The dominance of protruding areas (two thirds of the residues in the mimotopes have percentages of exposure greater than $60 \%$ ) and the presence of a region with alternating sign in the electrostatic potential (Fig. 2C) are compatible with favourable antigen-antibody interactions. However, given the homogeneous electropositive nature and the magnitude of the PB potential values (Fig. 2C), it seems also reasonable to predict a weak ionic activity associated to these IgE-binding surfaces. Since it has been proposed that strong electrostatic interactions should be expected in high-affinity antibody-antigen complexes whereas weaker electrostatic activity inherent to less specific contacts should be indicative of cross-reactivity (Sinha et al., 2002), one can speculate that these surfaces should preferably exhibit cross-reactive behaviour.

Regardless the nature of the IgE-binding interactions, the results provided by OAS and SYS mimotopes taken together point clearly to a particular surface region of Pru p 3 (Fig. 2) which has emerged before from rather different approaches. It must be stressed that the surface areas depicted by both mimotopes nicely match a great part of the IgE-epitopes previously reported by our group after following different methodologies (Garcia-Casado et al., 2003). For instance, on the theoretical basis of individual exposure and electrostatic features of all the amino acids of Pru p 3 , residues $\mathrm{N}_{36}, \mathrm{R}_{39}, \mathrm{~T}_{40}, \mathrm{R}_{44}$ and $\mathrm{S}_{76}$ were proposed to participate actively in $\mathrm{IgE}$ binding and indeed, a triple mutant R39A/T40A/R44A exhibited a 5fold decrease in the IgE-binding capacity compared with the 


\begin{tabular}{|lll|}
\hline Allergen & IgE-binding region & Common residues \\
\hline & $35 \quad$ 4676 79 & \\
Pru p 3 & NNLRTPDRASIPY & \\
Pru ar 3 & NNLRT PDRTNIPY & $11 / 13$ \\
Pru d 3 & NNLRTADRANVPY & $10 / 13$ \\
Zea m 14 & NNARTADRASI PY & $9 / 13$ \\
Mal d 3 & NGLRTADRTNVPY & $8 / 13$ \\
Pru av 3 & NNLKTADRTNVPY & $8 / 13$ \\
Cit s 3 & NAART PDRT SIPY & $8 / 13$ \\
Hev b 12 & NNAKTADRTNIPY & $8 / 13$ \\
Cor a 8 & NDARTSDRSNIPY & $8 / 13$ \\
Fra a 3 & NSMKTADRQNVPY & $7 / 13$ \\
Vit v 1 & NSAKTGDRASVPY & $7 / 13$ \\
Tri a 14 & HNQRSSDRSNLPY & $7 / 13$ \\
Amb a 6 & NNSKTADRAVKPD & $7 / 13$ \\
Lyc e 3 & LGQKTVDRANIPY & $6 / 13$ \\
Par j 1 & DGEKTLQRHVDSK & $3 / 13$ \\
Par j 2 & SEEKTEQKETTT- & $1 / 13$ \\
\hline
\end{tabular}

Fig. 3. Alignment of the amino acid sequence of the IgE-binding region of Pru p 3 defined here with the equivalent sequence of LTP allergens. Position numbers correspond to the Pru $\mathrm{p} 3$ sequence.

native allergen (Garcia-Casado et al,, 2003). Moreover, results of immunoblots with synthetic decapeptides overlapping by 5 amino acids together with theoretical analyses led us to identify $3 \mathrm{IgE}$-epitopes composed of the sequence segments $10-25$, 31-45 and 71-80 (Garcia-Casado et al., 2003). Note that all the residues in OAS and SYS mimotopes here described happen to be included in the second and third epitope, except $\mathrm{A}_{46}$ and $\mathrm{P}_{70}$ that correspond just to the end positions between these 2 segments. Regarding the first epitope, non-detected here, it is interesting to note that the segment 10-25 has been reported to overlap with one relevant region involved in $\operatorname{IgE}$ recognition described in Par j 1, a major allergen of Parietaria pollen (Colombo et al., 1998).

The fair agreement between the surface area of Pru $\mathrm{p} 3$ with IgE-binding capacity identified here and the regions proposed before as potential epitopes by our group can be overemphasized. Given the rather different methodological nature of phage display technology employed in this work to derive mimotopes and immunoblots with synthetic peptides or the fully theoretical approaches considered in our previous research to identify epitopes, this coincidence must be highlighted. The contiguous surface area spanned by residues near the loop $\mathrm{H} 2 \mathrm{H} 3$ together with the sequence segment 76-79 in the C-terminus seems thus a strong candidate to an ultimate IgE-binding region on this benchmark member of the LTP panallergens.

The alignment of the amino acid sequence of the Pru p 3 IgE-binding region here defined with the equivalent sequences of allergic LTPs from several plant foods and pollens (Fig. 3) indicated a high variability in the degree of similarity to the Pru p 3 region. Such similarity could determine the frequency of cross-reactions among several Rosaceae fruits found in the Mediterranean population, as well as between peach and some vegetables or nuts (Salcedo et al., 2007). Conversely, the divergence detected in several LTP allergens could also explain the limited (wheat Tri a 14), or even null cross-reactivity
(Parietaria Par j 1) described between peach and wheat or peach and these pollens (Salcedo et al., 2007; Palacin et al., 2007).

The power of the phage display technique must be finally highlighted as the results presented in this work are in excellent agreement with others reported before (Garcia-Casado et al., 2003; Borges et al., 2007). This technique can be especially important in food allergens as LTPs that involve mainly conformational epitopes. A wider use of this technique might undoubtedly facilitate the characterization of IgE-epitopes on different allergens (Riemer et al., 2004; Sharav et al., 2007; Partidos and Steward, 2002).

\section{References}

Aalberse, R.C., 2000. Structural biology of allergens. J. Allergy Clin. Immunol. $106,228-238$.

Baker, N.A., Sept, D., Joseph, S., Holst, M.J., McCammon, J.A., 2001. Electrostatics of nanosystems: application to microtubules and the ribosome. Proc. Natl. Acad. Sci. U.S.A. 98, 10037-10041.

Borges, J.P., Barre, A., Culerrier, R., Archimbaud, N., Didier, A., Rouge, P., 2007. How reliable is the structural prediction of IgE-binding epitopes of allergens? The case study of plant lipid transfer proteins. Biochimie 89 , 83-91.

Colombo, P., Kennedy, D., Ramsdale, T., Costa, M.A., Duro, G., Izzo, V., et al., 1998. Identification of an immunodominant $\operatorname{IgE}$ epitope of the Parietaria judaica major allergen. J Immunol. 160, 2780-2785.

Cuesta-Herranz, J., Lazaro, M., de las Heras, M., Lluch, M., Figueredo, E., Umpierrez, A., et al., 1998. Peach allergy pattern: experience in 70 patients. Allergy 53, 78-82.

Cuesta-Herranz, J., Lazaro, M., Figueredo, E., Igea, J.M., Umpierrez, A., DeLas-Heras, M., 2000. Allergy to plant-derived fresh foods in a birch- and ragweed-free area. Clin. Exp. Allergy 30, 1411-1416.

Davies, J.M., O'Hehir, R.E., Suphioglu, C., 2000. Use of phage display technology to investigate allergen-antibody interactions. J. Allergy Clin. Immunol. $105,1085-1092$.

Diaz-Perales, A., Sanz, M.L., Garcia-Casado, G., Sanchez-Monge, R., GarciaSelles, F.J., Lombardero, M., et al., 2003. Recombinant Pru p 3 and natural Pru p 3, a major peach allergen, show equivalent immunologic reactivity: a 
new tool for the diagnosis of fruit allergy. J. Allergy Clin. Immunol. 111, $628-633$.

Dolinsky, T.J., Nielsen, J.E., McCammon, J.A., Baker, N.A., 2004. PDB2PQR: an automated pipeline for the setup of Poisson-Boltzmann electrostatics calculations. Nucleic Acids Res. 32, W665-W667.

Fernandez-Rivas, M., van Ree, R., Cuevas, M., 1997. Allergy to Rosaceae fruits without related pollinosis. J. Allergy Clin. Immunol. 100, 728-733.

Fernandez-Rivas, M., Gonzalez-Mancebo, E., Rodriguez-Perez, R., Benito, C., Sanchez-Monge, R., Salcedo, G., et al., 2003. Clinically relevant peach allergy is related to peach lipid transfer protein, Pru p 3, in the Spanish population. J. Allergy Clin. Immunol. 112, 789-795.

Ferreira, F., Wallner, M., Breiteneder, H., Hartl, A., Thalhamer, J., Ebner, C., 2002. Genetic engineering of allergens: future therapeutic products. Int. Arch. Allergy Immunol. 128, 171-178.

Folgori, A., Tafi, R., Meola, A., Felici, F., Galfre, G., Cortese, R., et al., 1994. A general strategy to identify mimotopes of pathological antigens using only random peptide libraries and human sera. EMBO J. 13, 2236-2243.

Ganglberger, E., Grunberger, K., Sponer, B., Radauer, C., Breiteneder, H., BoltzNitulescu, G., et al., 2000. Allergen mimotopes for 3-dimensional epitope search and induction of antibodies inhibiting human IgE. FASEB J. 14 2177-2184.

Garcia-Casado, G., Pacios, L.F., Diaz-Perales, A., Sanchez-Monge, R., Lombardero, M., Garcia-Selles, F.J., et al., 2003. Identification of IgE-binding epitopes of the major peach allergen Pru p 3. J. Allergy Clin. Immunol. 112, 599-605.

Jensen-Jarolim, E., Leitner, A., Kalchhauser, H., Zurcher, A., Ganglberger, E. Bohle, B., et al., 1998. Peptide mimotopes displayed by phage inhibit antibody binding to Bet $\mathrm{v} 1$, the major birch pollen allergen, and induce specific IgG response in mice. FASEB J. 12, 1635-1642.

Jensen-Jarolim, E., Wiedermann, U., Ganglberger, E., Zurcher, A., Stadler, B.M., Boltz-Nitulescu, G., et al., 1999. Allergen mimotopes in food enhance type I allergic reactions in mice. FASEB J. 13, 1586-1592.

Kanny, G., Moneret-Vautrin, D.A., Flabbee, J., Beaudouin, E., Morisset, M., Thevenin, F., 2001. Population study of food allergy in France. J. Allergy Clin. Immunol. 108, 133-140.

Larche, M., Akdis, C.A., Valenta, R., 2006. Immunological mechanisms of allergen-specific immunotherapy. Nat. Rev. Immunol. 6, 761-771.

Luzzago, A., Felici, F., Tramontano, A., Pessi, A., Cortese, R., 1993. Mimicking of discontinuous epitopes by phage-displayed peptides. I. Epitope mapping of human $\mathrm{H}$ ferritin using a phage library of constrained peptides. Gene 128 , 51-57.

Myers, M.A., Davies, J.M., Tong, J.C., Whisstock, J., Scealy, M., Mackay, I.R., et al., 2000. Conformational epitopes on the diabetes autoantigen GAD65 identified by peptide phage display and molecular modeling. J. Immunol. $65,3830-3838$

Ortolani, C., Ispano, M., Pastorello, E., Bigi, A., Ansaloni, R., 1988. The oral allergy syndrome. Ann. Allergy 61, 47-52.
Pacios, L.F., 1994. Arvomol/contour: molecular surface areas and volumes on personal computers. Comput. Chem. 18, 377-385.

Pacios, L.F., 2001. Distinct molecular surfaces and hydrophobicity of amino acid residues in proteins. J. Chem. Inf. Comput. Sci. 41, 1427-1435.

Palacin, A., Quirce, S., Armentia, A., Fernández-Nieto, M., Pacios, L., Asensio, T., et al., 2007. Wheat lipid transfer protein is a major allergen associated with baker's asthma. J. Allergy Clin. Immunol. 120, 1132-1138.

Partidos, C.D., Steward, M.W., 2002. Mimotopes of viral antigens and biologically important molecules as candidate vaccines and potential immunotherapeutics. Comb. Chem. High Throughput Screen. 5, 15-27.

Pasquato, N., Berni, R., Folli, C., Folloni, S., Cianci, M., Pantano, S., et al., 2006. Crystal structure of peach Pru p 3, the prototypic member of the family of plant non-specific lipid transfer protein pan-allergens. J. Mol. Biol. 356, 684-694.

Pastorello, E.A., Robino, A.M., 2005. Clinical role of lipid transfer proteins in food allergy. Mol. Nutr. Food Res. 48, 356-362.

Pastorello, E.A., Farioli, L., Pravettoni, V., Ortolani, C., Hispano, M., Monza, M., et al., 1999. The major allergen of peach (Prunus persica) is a lipid transfer protein. J. Allergy Clin. Immunol. 103, 520-526.

Riemer, A., Scheiner, O., Jensen-Jarolim, E., 2004. Allergen mimotopes. Methods 32, 321-327.

Salcedo, G., Sanchez-Monge, R., Diaz-Perales, A., Garcia-Casado, G., Barber, D., 2004. Plant non-specific lipid transfer proteins as food and pollen allergens. Clin. Exp. Allergy 34, 1336-1341.

Salcedo, G., Sanchez-Monge, R., Barber, D., Diaz-Perales, A., 2007. Plant nonspecific lipid transfer proteins: an interface between plant defence and human allergy. Biochim. Biophys. Acta 1771, 781-791.

Sanchez-Monge, R., Lombardero, M., Garcia-Selles, F.J., Barber, D., Salcedo, G., 1999. Lipid-transfer proteins are relevant allergens in fruit allergy. J. Allergy Clin. Immunol. 103, 514-519.

Sharav, T., Wiesmuller, K.H., Walden, P., 2007. Mimotope vaccines for cancer immunotherapy. Vaccine 25, 3032-3037.

Sinha, N., Mohan, S., Lipschultz, C.A., Smith-Gill, S.J., 2002. Differences in electrostatic properties at antibody-antigen binding sites: implications for specificity and cross-reactivity. Biophys. J. 83, 2946-2968.

Sub-Committee on Skin Tests of the European Academy of Allergology and Clinical Immunology, 1989. Skin tests used in type I allergy testing Position paper. Allergy 44 (Suppl. 10), 1-59.

van Ree, R., 2002. Clinical importance of non-specific lipid transfer proteins as food allergens. Biochem. Soc. Trans. 30, 910-913.

Wang, J., Breslin, M.J., Coleman, P.J., Duggan, M.E., Hunt, C.A., Hutchinson, J.H., et al., 2004. Non-peptide alpha v beta 3 antagonists. Part 7. 3substituted tetrahydro-naphthyridine derivatives. Bioorg. Med. Chem. Lett. $14,1049-1052$.

Zuidmeer, L., van Ree, R., 2007. Lipid transfer protein allergy: primary food allergy or pollen/food syndrome in some cases. Curr. Opin. Allergy Clin. Immunol. 7, 269-273. 